\title{
Enterprise Resource Planning (ERP) System Implementation: Promise and Problems
}

Mehmet C. Kocakülâh, (E-mail: Mkocakul@usi.edu), University of Southern Indiana Dana R. Willett, University of Southern Indiana

\begin{abstract}
The experiences of the two businesses presented here correlate well with the success factors identified in the literature related to implementation of enterprise resource planning systems. The importance of successful ERP system planning and deployment becomes evident when consideration is given to the resources companies devote to these projects and the advantages promised and often realized as a result of business process improvement through ERP. As enterprise resource planning continues to evolve, its importance seems likely to grow. This evolution will allow ERP to expand to serve smaller and smaller businesses and businesses with more specialized enterprise resource planning needs. To truly serve these institutions, ERP deployments must become more reliable through the further refinement of success factor analysis.
\end{abstract}

\subsection{Introduction}

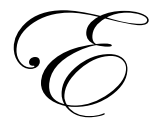

nterprise Resource Planning (ERP) systems change the way businesses do business. With promises of huge savings and competitive advantages, vendors sell at least $\$ 15$ billion of ERP systems each year with expected market growth to $\$ 50$ billion in annual ERP sales in the next three years, (Bingi, 1999). More than $50 \%$ of the Fortune 500 corporations today have already implemented ERP systems, (Grove, 2000), and $70 \%$ of the Fortune 1000 firms already have or will soon have ERP systems installed, (Bingi, 1999). Further, newly developed ERP packages target small and medium-size business with assurances that these software systems will bring big-business efficiencies at reasonable rates, (SAP Solutions, 2001). World Wide Web sites for ERP vendors host page upon page of business success stories attributed to ERP system implementation.

Such successes are measured in more than dollars and cents. If adequately supported by top management, have a good strategy and well-thought-out processes, ERP can reduce costs, shorten cycle time and improve customer satisfaction for any business. "In addition, it will help a business globalize its operations, expand its supply chain and customer relations base and move into hot new areas of e-commerce," (Wah, 2000).

ERP saves time, too. City accountants in Pasadena, California say financial documents that took up to ten days each month to process, print, and mail take only a day to post on-line with the local government's new ERP software, (Ferrando, 2000). Reports from IBM's Storage Systems division indicate that their ERP system helped reprice all their products in five minutes versus the five days required for the same job before the enterprise system began operation, (Bingi, 1999).

As with many silver linings, however, there are dark clouds-tales of ERP implementations gone wrong at huge and sometimes devastating costs. One study indicates that only one in every three "enterprise application initiatives is successful," (Buchok, 2000). In the nearly ten years since the first ERP system deployments, several companies have blamed major business problems on failed or troubled ERP roll-outs. In November 2000, Petsmart Inc.

Readers with comment or questions are encouraged to contact the authors via email. 
attributed a poor quarterly earnings report to an enterprise system that caused unusual inventory losses, (Mearian, 2000). Hershey Foods Corporation counted too much inventory and a 19\% dip in quarterly sales after ERP hassles in 1999, (Songini, 2000). Crown Crafts Inc. reported a 24\% drop in fourth quarter 1999 earnings after the company says an ERP system "caused manufacturing disruptions and missed shipments," (Gilbert, 2000). Likewise, W. W. Grainger Inc. identified over $\$ 23$ million in reduced earnings after nearly a year of struggle with an enterprise system that Grainger managers said undercounted inventory in six warehouses, (Stedman ${ }^{2}$, 2000). Also, add Volkswagen AG to companies with ERP difficulties. Repair shops and Volkswagen drivers waited weeks in early 2000 for spare parts deliveries while a team of ERP consultants worked to get software snags out of the way, (Stedman ${ }^{1}$, 2000).

Nevertheless, companies continue to consider ERP return worth the risk while asking vendors, consultants, and in-house implementation teams to ensure that an ERP deployment will not cost more than it must. To that end, enterprise system vendors work to improve software offerings, consultants tweak deployment methods, and ad-hoc ERP implementation teams search for guidance in industry benchmarks and proven success factors. To facilitate the discovery and analysis of such success factors, a summary of published information about them appears below, as do the results of interviews with the leaders of two ERP implementation teams. The experience of these two teams provides further anecdotal information about ERP system initiatives in small and medium-sized businesses with dissimilar human and financial resources while emphasizing the commonalities in their efforts.

\subsection{ERP Defined}

At its best, an enterprise resource planning system unites a business and all its functional areas under a company-wide information system. The ERP software integrates formerly isolated silos of automation and data under a common database and user interface. Information becomes available on-demand to assist in the coordination of business tasks as diverse as human resource management, accounting, manufacturing, distribution and supply-chain management, (Bingi, 1999). Through analysis of case studies, Rajagopal Palaniswamy and Tyler Frank discovered that "companies that have implemented ERP have made improvements in cross-functional coordination and business performance at various levels," (Palaniswamy, 2000). As business begin or continue their reorganization around processes by using more cross-functional teams, the importance of a seamless enterprise information system grows.

Similarly, these seamless systems comfortably cross national boundaries to help businesses compete in an increasingly global economy. "To be successful, a global enterprise must have accurate real-time information to control and coordinate the far-flung resources," (Bingi, 1999). Under a well-managed ERP system, multiple currencies and languages are supported, relevant taxes calculated, and country-specific import/export rules are automatically handled, (Bingi, 1999). The bi-directional and immediate flow of data between the information source (shop floor in Mexico City or help desk in New Delhi) and management helps create a more dynamic company that is flexible, fast, and responsive to changing market conditions and consumer demands. These dynamic companies are then better prepared to capture global levels of manufacturing efficiency, (Palaniswamy, 2000).

Indeed, a focus on manufacturing efficiency is central to the purpose of the earliest and most popular ERP systems. Current enterprise resource planning software emerged from other very popular information and control systems collectively called manufacturing resource planning (MRP II) systems. MRP II software helps companies capture information related to sales, production, inventory, and schedules to facilitate the control of the manufacturing and distribution process, (Palaniswamy, 2000). ERP systems improve upon the MRP II model by integrating data across the enterprise and making it available through a consistent user interface, (Bingi, 1999). Real-time access to this data allows the business to respond more rapidly to a customer base that, in many industries, demands greater customization of products - manufacturing is more "made-to-order" than "made-to-stock," (Palaniswamy, 2000).

To accomplish its goals in a variety of business environments, however, ERP systems must be customizable products, too. ERP vendors know that even among direct competitors, internal processes vary. One automobile manufacturer may use FIFO for inventory accounting while another uses LIFO. Budgets in one business may use actual costing figures while another uses a standard costing system. Enterprise system developers allow for these differences by building sets of adjustable parameters into the software program. These parameters store values that can 
be individually set to describe a company's unique method of operation, (Pinkus, 2000). Allen Pinkus, a vicepresident of an ERP development firm writes that the major sets of ERP parameters are as follows:

- $\quad$ System parameters, which define how the system is configured, the functional components it can run and the various technical considerations.

- $\quad$ Organization parameters, which define the structure of the company using the system-that is, the various departments or business processes and their interrelationships.

- Integration parameters, which are usually oriented to linking the financial modules to manufacturing and logistics and to the people who deal with analytical results.

- $\quad$ Functional domain parameters, which determine high-level aspects of sales, purchasing, manufacturing and other modules.

- $\quad$ Functional transaction parameters, which define how specific functions such as sales quotations and blanket purchase orders will look and operate.

(Pinkus, 2000)

Once a company loads its data, the parameters control the flow of information throughout the system. Employees enter business data once and it appears or is available where appropriate throughout the enterprise. Therefore, poorly established parameters bottleneck the flow of information and bad data races through the company as quickly as good data. This underscores the importance of taking an appropriate amount of time and care setting parameters and loading the initial data set. Recognizing the critical nature of this step in the implementation process, ERP vendors offer worksheets or questionnaires to help companies set parameters accurately and they sell kits that assist businesses in transferring legacy data into the new software. Quality ERP systems also include parameter "cross-reference checks, consistency validation techniques, error detectors, and system behavior simulators," (Pinkus, 2000).

Offering these kinds of tools, consulting services, and, of course, software systems, five ERP vendors dominate the market. SAP, Oracle Corporation, PeopleSoft Incorporated, J.D. Edwards \& Company, and Baan Company compete with several smaller software vendors for a chance to install ERP systems in a variety of businesses. Combined, the ERP marketers target products for nearly any type of institution-large or small, domestic or multinational, retail or manufacturing. Further, some enterprise software vendors promote products specially tuned to the needs of broad business segments such as aerospace, automotive, or telecommunications. ERP vendors also offer system solutions for various computer operating systems and network architectures-from Windows to Unix and mainframe to client/server.

Other ERP options tempt businesses, too, by offering flexibility in the depth and speed of ERP deployment. Companies may choose to implement only certain modules of the ERP solution, (Hill, 2000). For instance, a finance and accounting module could be deployed immediately with manufacturing or order processing modules to follow later. In this way, institutions limit their ERP implementation in the short-term with the ability to easily deepen their commitment later, (Bingi, 1999).

Companies interested in speedy ERP deployment, may choose one of the rapid implementation plans offered by many ERP vendors. In some cases, these quick implementations save both money and time at start-up with some compensating trade-offs. Where a traditional ERP deployment may cost over $\$ 100$ million dollars and take one or two years in a large business, successful rapid implementations reportedly save several million dollars and consume approximately $60 \%$ less time, (Konicki, 2000). These savings are balanced by the inability of client companies to customize the enterprise software for optimal performance with their businesses. Thus, long-term cost savings achieved through ERP efficiencies are reduced to only $50 \%$ or $60 \%$ of what the company could have expected with a slower, more traditional ERP deployment plan, (Konicki, 2000).

While the wide variety of options in ERP software reflects a maturing technology, enterprise systems are also evolving. Recently, ERP vendors have introduced modules that let disparate ERP systems communicate with one another. This facilitates supply chain management through the ERP system and beyond the boundaries of the individual business, ("ERP for the Internet Age"). In another evolutionary move, ERP developers have ported their 
products to the World Wide Web to allow businesses access to enterprise data on any Internet-connected computer, ("Turning a Corner"). Moreover, some ERP solutions are offered completely via the Internet through application service providers (ASPs)-outsourcing partners, who manage the software and hardware necessary to host a company's data, (Apicella, 2000). The ASPs promise the benefits of in-house enterprise resource planning systems, with cost savings in software, hardware, and the salaries of employees skilled enough to operate complex ERP systems. While, these developments in ERP systems add new complexities to the decision-making and subsequent implementation process for those companies considering an enterprise solution, the remaining discussion here focuses on enterprise resource planning systems where the software is deployed in-house to manage a business' internal data and processes.

\subsection{ERP Implementation Issues}

For over nearly a decade now, companies have learned important lessons as they established and began using enterprise resource planning systems. These lessons, as presented in industry reports and research, sound similar in certain respects. Further, they help identify common ERP implementation issues. Once they are grouped together, these issues fall into four areas:

1. The risks of ERP software customization,

2. The exercise of due diligence in the implementation process,

3. The management of project partners and consultants,

4. The alignment of the ERP system goals with business objectives.

Even with sophisticated software parameters optimally set on an ERP system created specifically for a certain business segment, it is unlikely that an unmodified ERP package will be a snug fit for a particular company. Consequently, many clients ask their ERP vendors for some customization. Most commonly, companies want to change the appearance or content of a system form or report. "Changing the report format, adding a column, or calculating additional fields of information is quite common and usually the first modification made," (Harris, 2000). Customizations like these may not be terribly complex, but they do add to the cost of and may delay an ERP implementation. Also, any future ERP system upgrades or software patches could overwrite the customization without notification.

More complex customization may be required by some businesses where unique business rules or policies must be represented in the underlying ERP software code. These modifications carry greater risks due to the intricate interrelationships of the software elements that knit together the ERP package. Customization of core ERP code may prove fatal to a deployment effort. "The majority of failed implementations are due to system code modifications that go beyond the workflow parameter settings found in most modern [ERP] packages," (Hibbler, 2000).

Many ERP implementation hassles are not, however, rooted in challenges with technology. Enterprise resource planning involves people, too. "An organization goes through a major transformation, and the management of this change must be carefully planned (from a strategic viewpoint) and meticulously implemented," (Bingi, 1999). This planning requires the diligence of ERP project leaders and top management. Lack of diligence often manifests itself in efforts to cut corners by skipping critical planning steps, (Bingi, 1999), or trimming training resources, (Wah, 2000). The importance of training end-users becomes apparent when businesses consider, "the people at the keyboards are now making decisions that commit the company directly into a live system," (Delsandaro, 1999). Again, bad data speeds through the ERP system just as fast a good data. With an ERP system, every user is a critical user of the software.

Yet another non-technical issue concerning ERP implementation involves the management of project partners and consultants. Consultants kick-start ERP for a company by providing critical technical advice derived from experience and by training employees on how to get the most from the new enterprise system. Finding qualified assistance for an ERP implementation may be difficult considering the necessary skills-familiarity with the ERP software, specific industry knowledge, and good interpersonal skills, (Bingi, 1999). Naturally, the scarcity of these experts makes them expensive and, therefore, a resource to be used wisely. As important as it is to get the right con- 
sultants in the door, ERP project managers must know how to get them out the door as soon as is practical. "Experts say that when users fail to plan for disengagement, consulting fees can run wild," (Delsandro, 1999). Considering that educated estimates for consulting fees total one to two times the cost of the ERP software package, poor management of consultants can easily ruin an implementation effort.

Likewise, failing to align the ERP system goals with business objectives often dooms enterprise system deployments. Some companies mistakenly approach an ERP implementation as a technical challenge to be primarily handled by the IT department. "Implementing any integrated ERP solution is not as much a technological exercise but an 'organizational revolution,"' (Bingi, 1999). The company must want to reorganize business processes to get the most out of the ERP system and this desire must be clearly articulated across the institution in order to quell resistance to change in the form of "turf" battles, (Wah, 2000). These conflicts arise when business managers see the ERP system as a tool for stripping away their control and authority over old business practices.

It is not enough, however, that the ERP system goals and the business objectives are aligned. The business objectives must also be reasonable with regard to the ERP system. Managers looking for rapid return on investment through ERP will likely be disappointed. ERP systems may not begin to show a good ROI until after five years of operation, (Wah, 2000). Any expectations for earlier return could damage management support for the ERP system resulting in the project being inappropriately branded a failure.

\subsection{ERP Success Factors}

Identifying and understanding the critical issues for ERP implementation helps define factors that must be executed correctly in order to get an enterprise system off to a good start. These success factors appear in various forms throughout ERP literature as tips, hints, critical issues, or just plain advice. When collected, they fall into two broad categories:

1. $\quad$ ERP System Planning Success Factors

2. $\quad$ ERP System Implementation Success Factors.

ERP System Planning Success Factors include securing the focused attention and support of top management, establishing the willingness of the institution to reengineer business processes, forming the cross functional ERP team, and finding the ERP system that matches specific business goals. ERP System Implementation Success Factors include establishing project control, generating and sustaining project momentum, severely limiting ERP system customization, creating ERP system performance measures, and ensuring quality user training. While these success factors are organized here in an original manner, the success factors themselves are paraphrased from the work of Richard Alvarez, Prasad Bingi, Joe Comerford, J.W. Dysart, Jayanth Godla, Steve Konicki, Sharon McDonnell, Andrew Osterland, Maneesh Sharma, Louisa Wah, and Sam Wee as cited below.

The items listed as ERP System Planning Success Factors are not necessarily organized by their importance. Rather, securing the focused attention and support of top management is listed initially because it is likely to be the first step performed as a company begins the process of planning for an ERP system. Once top management begins actively backing an ERP project, work on this factor, however, is not complete. Upper management support must be sustained throughout the ERP planning and implementation process. Indeed, "what makes ERP projects challenging is that in order to be successful, it is critical to address all of these factors at the same time," (Wee, 2001).

A company's top managers must make the ERP implementation one of the top four or five priorities for the company to achieve project success according to research conducted by Benchmarking Partners, (Wee, 2001). This priority attention sends strong signals throughout the institution that cooperation on the ERP project is expected and that success is anticipated, (Comerford, 2000). "Top management needs to constantly monitor the progress of the project and provide direction," (Bingi, 1999). To effectively monitor, executive management should be provided with enough information to give them a "complete understanding of the project," (Alvarez, 2000). 
This understanding of the ERP project should evolve into the second success factor listed under system planning: establishing the willingness of the institution to reengineer business processes. Quality ERP systems feature business processes that are often considered to be industry best practices. Therefore, when a company's processes differ from those modeled in the ERP software, the company should at least consider reengineering its way of doing things. Process reengineering should be done before beginning the installation of the ERP software, (McDonnell, 2000), and continue after users learn more about how the new system works, (Wee, 2001).

Ideally, users will be involved in the ERP implementation project from the beginning. Creating a cross functional ERP implementation team comprised of the company's best people helps smooth the ERP system selection and implementation process, (Wee, 2001). The best team members understand the "overall needs of the company" and are well aware of industry best practices and company processes, (Bingi, 1999). User involvement from various functional areas of the business at the beginning of the project ensures that lines of communication are open and that information about the ERP project is shared. Once the rollout of the new ERP system is ready, the implementation team also helps to build acceptance of the new system by sharing what they know about the benefits of ERP with co-workers.

The changes brought about by the ERP system implementation will more likely be positively received if the system selection is based on what helps the business achieve its objectives. The process of selecting the right ERP system begins, then, with taking the ERP project out of the technical arena and putting it into a business perspective, (Osterland, 2000). "Executives and consultants who have worked with ERP recommend that an organization clearly define what it wants ERP to accomplish," (Dysart, 2000). With these goals in mind, selection of the right ERP system for a particular business becomes easier. Each member of the ERP implementation team has a clear idea what evaluation criteria to use as a reference for rating the various vendor offerings.

Once an ERP system has been selected, the project moves into the implementation phase. The first of the ERP System Implementation Success Factors is establishing project control. From a project manager's perspective this involves controlling internal politics and controlling the various implementation partners hired from outside the company (consultants and vendors), (Osterland, 2000). Stated another way, project control centers around communication-"manage expectations at all levels of the organization so everyone knows what's ahead, what's expected of them, and how the change will impact their work lives on a daily basis," (Wee, 2001). The ERP implementation team should help control internal politics by keeping channels of communication open throughout the enterprise. Clear, complete contracts with consultants help manage expectations and will likely assist in keeping costs down, too, (Osterland, 2000).

The second success factor in the implementation phase helps keep costs in line, too: generating and sustaining project momentum. Successful ERP deployments require a balance between two leadership qualities-speed and effectiveness. "These opposites can coexist in an ERP project, "writes Sam Wee, "if you move quickly enough to ensure that people don't lose their focus and motivation, while at the same time you move slowly enough to manage change, get buy-in from staff and communicate," (Wee, 2001). Swift decisive action controls costs by limiting expensive consultant time wasted on change management, by improving efficiencies through greater user productivity based on rapid buy-in, and by driving down lost time due to miscommunication.

Momentum is also preserved by severely limiting ERP software customization. Stated simply, "customization adds complexity, which increases the danger of a botched implementation," (Dysart, 2000). Any modification to the ERP system increases costs now and again later because customizations have to be reprogrammed after every ERP software upgrade or patch. If selected properly during the planning phase, the ERP software should come closer than any other ERP system to fitting the businesses' way of doing business. Overwhelming anecdotal evidence indicates that ERP software customization often leads to a failed enterprise system deployment.

Even the success of a smooth ERP system implementation may go unappreciated if performance measures are not put in place. Some of the early positive effects of ERP may go unnoticed without appropriate benchmarks. These performance indicators also signal when the ERP system is not performing as it should and may need adjust- 
ment, (Osterland, 2000). Establishment of these performance measures also offers a focal point for employees who are encouraged to learn new systems and software where achievable goals are apparent.

User training on the new ERP system represents the last success factor in the implementation phase and it is the most persistent factor in the long-term success of enterprise systems. Consultants note that businesses frequently budget too few dollars for training, (Konicki, 2000). Some ERP experts estimate that $30 \%-40 \%$ of undertrained workers "will not be able to handle the demands of the new system, (Bingi, 1999). Surveys and computerbased training tools help identify employees who need additional ERP instruction in order to get the most from the new system, (Callaway, 1999).

\subsection{Two Businesses Plan and Implement ERP Systems: Common Success Factors}

Success with the planning and implementation factors just described helped Anchor Industries and Rexam Closures deploy their ERP systems. The ERP implementation project managers of these two companies reflected on the challenges they encountered and tactics they employed while working through the ERP planning and deployment process. Both feel their attention to specific success factors helped them avoid problems and ensured a smooth enterprise implementation. While these companies are distinct in their organizational structures, resources, and approach to ERP, both businesses ultimately identified common success factors and managed these factors to success.

Anchor Industries Inc., based in Evansville, Indiana, is a privately held custom fabric product manufacturer. Their sales offerings include tents, canopies, awnings, and safety pool covers, (Anchor Industries Home Page, 2001). With one manufacturing facility in Bradenton, Florida and another in Evansville, Indiana, Anchor creates and sells approximately $\$ 40-\$ 50$ million of products to government entities, corporate clients, and individuals. Anchor successfully installed and uses J.D. Edwards' World software for enterprise resource planning. Project manager , Anchor's IT director, led the ERP implementation project in 1999.

Project manager, an operations/forecast analyst at Rexam Closures \& Containers, directs an ERP system implementation effort at Rexam's Evansville plant and was involved in a successful ERP deployment in another Rexam facility in the United Kingdom. With a corporate headquarters in London, England and 25 plant sites around the world, Rexam manufactures packaging for the beauty, beverage, healthcare, and food industries. The publicly traded company (REX.L) generates $\$ 4$ billion in sales annually. Rexam has implemented J.D. Edwards' OneWorld ERP system software in the United Kingdom with the intention of completing a similar deployment in the Evansville facility by January 2003.

Both Anchor and Rexam began considering implementation of an enterprise resource planning system after the MRP II systems they had been using began showing signs of age. With potential Year 2000 (Y2K) issues related to the MRP II system, replacement or upgrade of the manufacturing software became a business imperative for Rexam in the U.K. and Anchor in Evansville. The potential problems with date-based software errors connected with Y2K made the need for a new enterprise system an easier sell to top management in both companies. The both project managers worked throughout the ERP planning and implementation process to keep upper management informed and involved in the deployment.

Once top management support was secure, both project leaders formed cross-functional planning and implementation teams. One project manager recalled that, "user buy-in was recognized from the beginning." he was the only IT person at Anchor during the deployment and that he needed help from the company's "power users," (skilled users of the old MRP II system) to help select the new ERP system and to help train others to use it. Ten "power users" from various functional areas of the company joined the project manager on the ERP team and began investigating potential enterprise system vendors. At Rexam, Project manager's team included eight members: two from finance and accounting, one from order processing, two from manufacturing, and two from IT. The Rexam ERP team met two times a week for the first two months to pare a list of 15 potential system vendors down to eight.

The Rexam team further vetted vendors by developing a document (with the help of an ERP consultant) that contained a specific set of business problems, data, and process requirements. Only three vendors were allowed 
to offer complete system demonstrations before J.D. Edwards was selected. The Anchor ERP team created a uniform evaluation tool based on business needs determined by the various functional areas of the enterprise. The evaluation tool was used to review the various ERP vendor offerings and to conduct a cost-benefit analysis of each proposal. One project manager commented that the evaluation tool kept the ERP team focused on the business issues related to the new system and allowed the team to more easily select the right ERP software for Anchor.

As both businesses moved into the implementation phase of the project, they used several tactics to succeed with the project control factor. At Anchor, Project manager restricted the use of consultants on the project by limiting them to helping ERP team members get up to speed with the ERP software faster. Internal politics at Anchor was managed by clear communication through the ERP team to the various functional areas of the business. The Rexam's ERP team served the same purpose. The Rexam's ERP deployment benefited from project leadership by those with project management experience as opposed to purely technical (IT) skills.

While neither project manager specifically mentioned project momentum as a factor they considered in their ERP deployment, both companies moved quickly to implement the new systems. Once J.D. Edwards' World software won at Anchor, the system was running within 13 months. Using a similar timeframe, Rexam's U.K. operation implemented the J.D.Edwards OneWorld ERP system during 1999. The U.K. plant moved quickly by choosing to eliminate customization of the ERP system-using what they call a "vanilla" version of the software. Anchor eschewed customization, too. Before the ERP system began operation there, only a small change was made to allow Anchor to print their own business forms rather than using J.D. Edwards' pre-printed, forms because of expense involve.

Neither company discussed the specifics of performance measures used to evaluate the ERP systems, but both noted that the value of the implementation was and is being measured in business terms. The ERP system at Anchor has significantly improved the flow of information through the business and has changed $40 \%-50 \%$ of internal processes. The process improvements at Rexam's U.K. facility since the ERP system began operation. Further, the OneWorld software is on track to pay for itself in two years through savings in business operations.

As a success factor, both project leaders mentioned training. Considerable time and money was devoted to preparing employees to use the new system. Project Manager suggests that businesses take a core team and train them intensively and let that team help train others in the enterprise. At Anchor, they used this approach with mixed results. Some users, he says, were left behind and had to be retrained. He praises computer-based training tools as a way to allow some ERP users to learn at their own pace. One project manager also adds that training is never complete as long as there are additional opportunities to leverage the ERP system for better business performance.

\subsection{Suggestions for future research}

Future areas for research related to Enterprise Resource Planning Systems include examinations of the impact on the balance sheet for implementation, successes of businesses converting to or adding Customer Resource Management Systems, and a longitudinal look at successful maintenance and compliance techniques for ERP systems. Literature review indicates that few businesses have "opened the books" for research into the impact of ERP implementation on the balance sheet. An exploration of how actual accounting data may compare to perceptions of the success of ERP would also be enlightening.

\section{References}

1. Alvarez, Richard S. "Strategies for Successful Implementation of an Integrated Enterprise Suite." Syllabus February 2000: 42-45.

2. $\quad$ Apicella, Mario. "The Hands That Move Your Business." InfoWorld 26 June 2000: 44-45.

3. Baan Industries Home Page. 22 April 2001. http://www.baan.com/industries/index.htm.

4. Bingi, Prasad, Maneesh K. Sharma, and Jayanth K. Godla. "Critical Issues Affecting an ERP Implementation.” Information Systems Management Summer 1999: 7-15. 
5. $\quad$ Buchok, James. "Failed Initiatives." Computing Canada 14 April 2000: 10.

6. Callaway, Erin. "Power Trainers.” Inside Technology Training February 1999: 18-22.

7. $\quad$ Collier, Nikki. Personal interview. 10 April 2001.

8. $\quad$ Comerford, Joe. "Plan the Complexity Out of ERP Implementations." Business Journal 18 February 2000: 26-27.

9. Delsandro, Christopher R. "Enterprise Resource Planning Software: The Hidden Costs." 3 August 1999. 22 April $2001<$ http://www.burgee.com/loyola/757delsa.htm>.

10. Dysart, J.W. “Planning for Real-Time Information.” Banking Strategies May/June 2000: 6-8.

11. "ERP for the Internet Age." Modern Materials Handling August 2000: 43-45.

12. $\quad$ Ferrando, Tom. "ERP Systems Help with Integration." American City \& County August 2000: 12.

13. Gilbert, Alorie, and Jennifer Mateyaschuk. "A Question of Convenience." InformationWeek 21 February 2000: 34-36.

14. Grove, Robert. "Beyond ERP and SCM, Enter the Supply Web." Business Times 14 July 2000.

15. Harris, Russ. "Customization Versus Standardization: Striking a Balance in ERP Software." Machine Design 20 July 2000: S64-S66.

16. Harvey, Steve. "How Much for Midrange ERP." Planet IT 27 September 2000, 22 April 2001 <http://www.planetit.com/docs/PIT200000927S0001>.

17. Hibbler, Fredric. "ERP Systems: Worth the Pain." Wireless Week 26 June 2000: 57.

18. Hill, Suzette. "ERP: It’s All in How You View It.” Apparel Industry October 2000: 22-26.

19. Konicki, Steve. "Fast Deployments at a Price." InformationWeek 23 October 2000: 77-83.

20. McDonnell, Sharon. "Squeezing More Out of ERP” Computerworld 2 October 2000: 56-57.

21. Mearian, Lucas. "CEO: SAP Installation Caused Problems." Computerworld 27 November 2000: 20.

22. $\quad$ Osterland, Andrew. "Blaming ERP." CFO January 2000: 89-92.

23. Palaniswamy, Rajagopal, and Tyler Frank. "Enhancing Manufacturing Performance with ERP Systems." Information Systems Management Summer 2000: 43-55.

24. Pinkus, Allen L. "ERP Systems for Coatings Manufacturers Must Have 'Grizzly Bear' Parameters." Paint \& Coatings Industry November 2000: 94-96.

25. SAP Solutions. 16 April 2001. <http://www.sap.com/solutions/workplace/smallbusiness.htm>.

26. Songini, Marc L. "Halloween Less Haunting for Hershey This Year." Computerworld 6 November 2000: 12.

27. Stedman ${ }^{1}$, Craig. "ERP Problems Put Brakes on Volkswagen Parts." Computerworld 3 January 2000: 8.

28. Stedman 2 , Craig. "ERP Woes Hit Grainger Again." Computerworld 10 January 2000: 8.

29. “Turning a Corner." Economist 29 July 2000: 63-64.

30. Wah, Louisa. "Give ERP a Chance." Management Review March 2000: 20-24.

31. Webster, David. Personal Interview. 22 April 2001.

32. Wee, Sam. "Juggling Toward ERP Success." ERP News 25 February 2001 <http://www.erpnews.com/erpnews/erp904/02get.htm>.September 9, 2001. 
Notes 